\title{
Políticas de Liberalização do Comércio de Serviços (GATS) COM RegulaçÃo Redistributiva
}

\author{
Umberto Celli Junior(i)
}

\begin{abstract}
Resumo: A crise sem precedentes por que passa a economia internacional, provocada, em larga medida, pelo apego irrestrito a certos dogmas neoliberais, reforça a tese da necessidade de regulação da economia. O setor de serviços, em face de suas características, não pode ser compreendido sem que se leve em consideração a importância de um quadro regulador bem estruturado e afinado com as necessidades de inclusão social da população dos países em geral. Em alguns países da América Latina, a experiência com a aber tura desacompanhada de uma regulação eficaz no setor de serviços revelou-se desastrosa. As reflexões sobre uma regulação redistributiva no setor de serviços podem servir de inspiração à adoção de mecanismos de controle e fiscalização de certas atividades econômicas e financeiras movidas pela fé inabalável na capacidade de autorregulação dos mercados.
\end{abstract}

Palavras-chave: Comércio de Serviços, GATS, Liberalização, Regulação, Regulação Redistributiva, Policy Space.

Abstract: The unprecedented crisis affecting the international economy caused, to a large extent, by the unconditional faith in certain neoliberal dogmas, reinforces the need for the economic regulation. Given its special nature, one cannot fully understand the services sector without taking due regard of the importance of a regulatory framework well structured and attuned with social inclusion needs of countries population as a whole. In certain Latin American countries, market opening processes that overlooked the need for an effective regulatory framework were disastrous. The reflections on a redistributive regulation in the services sector may eventually inspire the adoption of control and monitoring mechanisms on certain financial and economic activities which have been operating based on the immovable faith in the self-regulation ability of the markets.

Keywords: Trade in Services, GATS, Liberalization, Regulation, Redistributive Regulation, Policy Space.

(*) Professor livre-docente de Direito Internacional da USP e do Programa de pós-graduação em Integração da América Latina _ PROLAM/USP. E-mail: umbcelli@usp.br. Recebido em 25.5.09 e aceito em 26.6.09. 


\section{INTRODUÇão}

Em anos recentes, a arguição feita por países em desenvolvimento (PED) em foros multilaterais em favor da reafirmação do direito de regular setores de suas economias com o propósito, dentre outros, de manter o policy space (isto é, espaço para fazer políticas públicas) foi combatida com veemência por economistas e juristas neoliberais que se recusavam a admitir que a abertura comercial não havia sido suficiente para gerar desenvolvimento, corrigir assimetrias econômicas e, o que é mais relevante, diminuir a pobreza.

O modelo ortodoxo de liberalização comercial parece ter eclipsado muitas das perspectivas dos PED sobre como usar de modo efetivo esse espaço para regulação. Para seus defensores, o encolhimento do espaço político para os governos dos PED na área de políticas comerciais (e industriais) seria, de fato, algo bom, pois evitaria que tais países cometessem erros ao adotarem políticas onerosas, quer por crenças enganosas no intervencionismo ou devido às políticas de grupos de interesse.

A (re) introdução na agenda multilateral e, em particular, na built in agenda do GATS do tema relacionado à necessidade de manutenção do espaço para adotar políticas públicas e de regulação voltadas ao desenvolvimento constituiria para economistas e juristas neoliberais um retrocesso ou a retomada de um protecionismo nos moldes de algumas décadas atrás. Para alguns deles, a insistente defesa da importância do tema da regulação e do policy space para os PED guardaria grande similaridade com um "bolero de Ravel", ou seja, não poderia haver algo mais tocado e mais desgastado pelo tempo.

A crise do sistema financeiro global internacional, com epicentro nos Estados Unidos, provocada pela inabalável crença na capacidade do mercado de autorregular-se, na regulação mínima ou na desregulação do mercado e da economia, colocou em xeque alguns dos dogmas neoliberais. Na reunião de cúpula do G-20, realizada em Washington em novembro de 2008, ficou acordado um rol de medidas visando a tornar viável uma maior regulação e supervisão dos mercados financeiros no âmbito global.

Quando a crise financeira atingiu a chamada economia real, ou seja, resultou em desaceleração de investimentos, queda de produção, importação e exportação, escassez de crédito e desemprego, aumentou a percepção na sociedade internacional de que o mercado necessita de mecanismos eficazes de controle e de proteção contra a ganância e a irresponsabilidade de alguns investidores e especuladores de todos os matizes e de governantes que não têm qualquer tipo de compromisso com o desenvolvimento sustentável, o bem-estar e a inclusão social de suas populações. A regulação dos mercados voltou a ser defendida mesmo por aqueles que até bem pouco tempo atrás a viam como um retrocesso, um instrumento de intervenção do Estado prejudicial ao crescimento da economia.

Na reunião do G-20, também ficou acordado que seriam retomados os esforços para destravar a Rodada Doha da Organização Mundial do Comércio (OMC), uma vez que a liberalização comercial poderia funcionar como um antídoto contra a crise. De fato, o incremento do comércio internacional de bens e serviços será crucial para amenizar essa crise financeira e econômica sem precedentes. As negociações da Rodada Doha precisam ser 
concluídas. Em julho de 2008, os países-membros não conseguiram chegar a um acordo para fechá-la. Enquanto, no setor de bens não agrícolas (Non-Agricultural Market Access NAMA), alguns membros como a Argentina, além de terem se oposto ao percentual de abertura negociado, pleitearam um tratamento especial para os denominados setores ou produtos sensíveis em agricultura, a Índia, dentre outros, demandou maior proteção por meio da adoção de mecanismos especiais de salvaguardas. No setor de serviços, embora o nível de ambição fosse bem menor, os membros demonstraram disposição de avançar nas negociações sobre regulamentação doméstica e de apresentar ofertas de compromissos em alguns setores.

A retomada das negociações da Rodada Doha ocorrerá nesse cenário pós-crise, no qual os excessos do liberalismo comercial e econômico e do mito do poder infalível de autorregulação do mercado deverão servir como reflexão para a adoção de novos rumos. Tanto o sistema financeiro quanto o econômico-comercial necessitam de regulação, de normas de controle e de fiscalização, sobretudo para assegurar a correção de assimetrias e proporcionar desenvolvimento sustentável.

Essa questão, aliás, é antiga na área do GATS. Afinal, o comércio de serviços contém setores sensíveis do ponto de vista das economias dos PED, mas que, se bem geridos e administrados, terão um enorme potencial de inclusão social. Nas negociações do GATS, a correção de assimetrias e a geração de desenvolvimento sustentável com alto índice de inclusão social só podem ocorrer se os PED dispuserem de espaço e autonomia para utilizar políticas ativas e instrumentos de política para promover sua capacidade de fornecimento de serviços, ampliar os processos de assimilação de novas tecnologias e buscar competitividade.

O objetivo deste artigo é exatamente o de demonstrar como essas reflexões sobre regulação, autonomia regulatória e espaço para condução de políticas públicas, que ora têm sido resgatadas por conta de uma crise financeira e econômica internacional sem precedentes, estiveram - ou, pelo menos, deveriam ter estado - subjacentes a qualquer programa viável de liberalização no âmbito do GATS. Essas reflexões podem ainda servir de estímulo à adoção de novos parâmetros de controle e fiscalização de alguns setores da economia.

\section{Conflito potencial entre Regulação Nacional e Liberalização do Comércio Internacional de Serviços}

Um aspecto relevante do GATS relaciona-se à capacidade dos membros de regular e de introduzir novas regulamentações sobre serviços dentro de seus territórios para atingir seus objetivos nacionais. À medida que a liberalização do comércio de serviços pode resultar na limitação da autonomia reguladora ou legislativa interna dos membros, na hipótese de as obrigações do GATS requererem a abolição ou a alteração de certas normas e regras e sua aplicação, constata-se um conflito potencial entre o direito de regular e o processo de liberalização. Isso parece indicar que a política nacional de regulação requer um reconhecimento especial vis-à-vis à liberalização do comércio. 


\section{REgUlação}

O termo regulação, como lembram Baldwin e Cave ${ }^{(1)}$, não possui conceito universalmente aceito. Tem distintos significados do ponto de vista político, econômico e jurídico, que, além disso, variam de país para país. De modo geral, a regulação é vista como uma atividade que restringe comportamentos e coíbe a ocorrência de certas práticas indesejáveis (red light concept). A regulação também pode ter por escopo viabilizar ou facilitar certas atividades (green light concept), como, por exemplo, o controle da utilização do uso de frequências para a prestação de alguns serviços de telecomunicações, sem o qual a própria comunicação se tornaria impossível. Nenhum desses conceitos, contudo, permite identificar a real abrangência, a influência e o impacto que a regulação pode exercer sobre a atividade econômica.

Dois enfoques substancialmente diferentes entre si, mas que contêm alguns elementos comuns, podem ser utilizados para verificação do alcance e do significado da regulação. No primeiro deles, a regulação consiste fundamentalmente no processo de elaboração de normas voltadas à promoção de objetivos econômicos e sociais específicos, cabendo a agências reguladoras independentes o exercício dessa função. Nesse contexto, distingue-se claramente o papel do Estado enquanto agente regulador de outras atividades governamentais tradicionais, tais como o bem-estar social, a distribuição de riqueza e o planejamento estratégico. O objetivo da regulação é predominantemente o de corrigir eventuais falhas do mercado; o Estado intervém apenas para ampliar e não para substituir os processos ou atores desse mercado. Políticas de redistribuição estariam normalmente fora do escopo da regulação. Esse modelo de regulação desenvolveu-se e consolidou-se principalmente nos Estados Unidos.

O segundo enfoque ou modelo é mais abrangente, porque incluiria atividades governamentais típicas associadas às do Estado regulador. À diferença do primeiro enfoque, a regulação não teria como escopo primordial a correção das falhas do mercado. Teria metas de distribuição (i. e., repartição da riqueza) e outros objetivos de política social e econômica. Esse modelo caracteriza-se por intervenção governamental mais intensa nos processos de mercado, muitas vezes até visando a eles se sobrepor. A participação do Estado em empresas e incentivos à economia bem como o planejamento econômico e de desenvolvimento são tidos como instrumentos legítimos de regulação. Sua adoção tem ocorrido com maior frequência em muitos países europeus e PED (KRAJEWSKI, 2003. p. 1-2).

De fato, com algumas nuances, esse é o modelo mais adequado para os PED. Não basta apenas uma regulação cujo objetivo seja o de primordialmente corrigir falhas do mercado. A intervenção estatal, via regulação, é um importante instrumento de desenvolvimento. ${ }^{(2)}$ Não

\footnotetext{
(1) Ver a respeito em Baldwin e Cave (1999. p. 2).

(2) Em artigo intitulado "Retorno ao pêndulo", Antonio Luiz M. C. Costa sublinha que "a cada trinta anos, mais ou menos, trocam-se as ideologias sobre a ação do Estado na economia". A crise financeira que assolou os Estados Unidos em 2008 tem provocado reflexões sobre a necessidade de uma maior intervenção do Estado para, dentre outros aspectos, "remediar a falta de regulamentação do setor financeiro". "Mais recentemente, o francês Dominique Strauss-Kahn, diretor-gerente do FMI, apelou aos demais governos com recursos para tanto que não se limitem à política monetária e recorram a políticas fiscais anticíclicas: "A necessidade de intervenção pública na economia está ficando mais evidente", disse ele ao jornal Financial Times em 7 de abril". Revista Carta Capital, ano XIV, n. 492, 23.4.2008. p. 23/26. Luiz Carlos Bresser-Pereira, em artigo intitulado "Fim da onda neoliberal", publicado no jornal Folha de S. Paulo, p. B 2, de 21.4.2008,
} 
nos moldes clássicos em que o Estado assumia funções empresariais e impedia a livre concorrência com setores da iniciativa privada. No caso de serviços, assim como foi no setor industrial, são necessárias políticas de desenvolvimento que não afastem o setor privado, mas que criem um ambiente de concorrência em benefício da população e, principalmente, assegurem a redistribuição de rend $a^{(3)} \mathrm{e} o$ acesso universal a serviços essenciais.

A regulação consistiria, assim, em um processo de influenciar, controlar e orientar atividades econômicas ou privadas por meio de políticas ou medidas governamentais. Seu propósito seria, pois, o de assegurar a implantação de políticas públicas de proteção a consumidores e a usuários, de estímulo à concorrência, de apoio à capacitação de fornecedores domésticos ou nacionais e de proteção ambiental, dentre outras. Mais importante ainda, a regulação teria por escopo assegurar o acesso universal aos serviços essenciais, particularmente dos segmentos mais pobres, vulneráveis e marginalizados da sociedade. Em suma, o objetivo último da regulação seria o de endereçar questões relacionadas à redistribuição de renda, à equidade, à acessibilidade, à qualidade e à segurança dos serviços. Isso não excluiria a necessidade de cuidar também da correção das falhas do mercado e da busca por maior eficiência econômica dos prestadores de serviços. ${ }^{(4)}$

Daí ser fundamental e, mais do que isso, condição para a liberalização internacional do mercado de serviços, a manutenção da autonomia reguladora e do policy space dos membros.

\section{As duas faces do processo de liberalização}

O termo liberalização pode ser entendido como um processo cujo objetivo é o de estabelecer um mercado mais aberto e competitivo. Isso requer a remoção de barreiras e obstáculos à entrada nesse mercado bem como a introdução de um regime de livre concorrência.

assim se manifestou: "Chegou ao fim a onda ideológica neoliberal que dominou o mundo nos últimos 30 anos no quadro da hegemonia americana. Dois fatos ocorridos nas últimas semanas marcaram esse fim inglório; de um lado, o socorro do banco de investimento Bear Stearns; de outro, as revoltas populares em vários dos 33 países hoje seriamente atingidos pelo aumento do preço dos alimentos". Para um estudo aprofundado sobre a evolução dos processos de regulação, ver Aguillar (2006).

(3) Como observado por Calix to Salomão (2002. p. 41), é "na redistribuição que deve ser identificada a grande função do novo Estado".

(4) Nesse tocante, Calix to Salomão ressalta que nunca "será possível coordenar convenientemente princípios como, por exemplo, os da livre iniciativa e da justiça social se ao último for dada uma interpretação meramente compensatória, ou seja, de que é preciso preservar a liberdade empresarial, compensando grupos menos favorecidos pelas injustiças (sociais) causadas pelo funcionamento natural do sistema". Uma perspectiva que não seja compensatória, diz ele, "mas, sim, estruturalista, permite dar, se não mais precisão, ao menos mais materialidade à coordenação entre princípios. Assim, identificar instrumentos regulatórios que interfiram e modifiquem as estruturas de poder econômico e disciplinem e orientem a forma de funcionamento das empresas públicas e privadas nos setores regulados pode ajudar a impedir que o funcionamento normal do sistema econômico leve à produção de desequilíbrios econômicos e sociais" (SALOMÃO FILHO, 2008. p. 16). Esse enfoque da regulação com viés claramente social parece também ser partilhado por outros autores brasileiros, dentre os quais, Diogo Coutinho. Para ele, a "noção de regulação pode admitir um viés redistributivo, especialmente se um pano de fundo típico a países em desenvolvimento for estendido”. Em sua análise sobre regulação, Coutinho, após citar autores que traçam uma distinção entre regulação econômica e regulação social, tais como Antony Ogus e Christopher Foster, assinala que "países em desenvolvimento podem e devem ver na regulação uma forma de cumprir, dentro de certos limites a respeito dos quais deve haver discussão ampla, uma certa 'tarefa inacabada' do Estado desenvolvimentista, submetido em grande escala a processos de privatização orientados por lógicas de curto prazo...” (COUTINHO, 2005. p. 137-160) 
Essa remoção de barreiras e obstáculos pode compreender tanto a adaptação de um sistema normativo, o que implicaria uma redução no conjunto de normas e regras vigentes, quanto a substituição desse sistema por outro com características bem distintas.

Sob essa perspectiva, verifica-se um conflito potencial entre a liberalização e a regulação. Há, contudo, situações em que determinadas práticas comerciais do setor privado resultam na criação de barreiras à entrada de novos concorrentes, o que gera a necessidade de regulação do mercado, especialmente no tocante à edição de regras de concorrência. Ocorre, assim, um fortalecimento mútuo dos dois processos, o de regulação e o de liberalização do mercado.

A liberalização do mercado tem duas faces: a interna e a internacional. Enquanto a liberalização interna visa a assegurar um mercado competitivo para os agentes econômicos domésticos, a liberalização internacional tem por escopo criar um ambiente competitivo para empresas estrangeiras. Contudo, na prática, muitas vezes, seus efeitos são coincidentes, razão pela qual nem sempre essas duas faces são facilmente diferenciáveis. Por exemplo, a legislação de muitos países (independentemente das esferas de poderes) estabelece uma série de requisitos (e.g., testes de necessidade econômica) para que uma loja de departamentos possa operar, o que pode ser visto como um obstáculo ao comércio de serviços varejista. Tais requisitos ou obstáculos aplicam-se tanto a operadores domésticos quanto a estrangeiros. A revogação desses requisitos implicaria simultaneamente uma liberalização interna e internacional.

De outro lado, também é certo que, na teoria, essas duas faces não coincidem necessariamente. O mercado de um determinado país pode ser amplamente aberto para operadores domésticos, dispondo de um ambiente de competitividade e concorrência e altamente restritivo ao acesso de operadores estrangeiros. Da mesma forma, o que é menos comum, pode esse mercado ser relativamente restritivo para agentes domésticos e aberto a operadores estrangeiros. Mas, como lembra Krajewski, é muito mais complicado para o governo de um país manter essa política. Usualmente, diz ele, "abrir o mercado para prestadores de serviços estrangeiros requer a liberalização interna por razões de natureza legal, política e prática". Assim, sustenta o autor, "na prática, a liberalização internacional frequentemente coincide ou reforça a liberalização interna". Essa relação é muito visível no GATS, já que a liberalização do comércio de serviços "pode requerer a abolição de algumas barreiras regulatórias, o que contribui para a liberalização interna". ${ }^{(5)}$

\section{Desregulamentação e privatização}

Há dois conceitos costumeiramente associados aos contextos de liberalização e de regulação: a desregulamentação e a privatização. Não se observa, no entanto, muita clareza no tocante à relação entre eles.

(5) Krajewski (2003. p. 5-6) (“...opening a market to foreign service suppliers also requires domestic liberalization because of legal, political and practical reasons.” “...international liberalization often coincides or reinforces domestic liberalization in practical terms." "Liberalization of trade in services may demand the abolishment of some regulatory measures and may hence contribute to domestic liberalization".) Acrescente-se, ainda, que, em março de 2003, o CCS regulamentou mecanismo denominado de liberalização autônoma, por meio do qual os membros podem assumir compromissos setoriais por vontade própria, independentemente de negociações na OMC. No entanto, esse mecanismo tem sido muito pouco utilizado pelos membros. 
A desregulamentação pode ser vista como um processo que visa a reduzir a quantidade e a densidade de normas e regras, de forma a permitir menos interferência estatal na economia ou sobre as forças de mercado. Nesse cenário, as normas e as regras seriam mais simples, transparentes e eficazes. Esse último componente (i. e., normas e regras mais simples, transparentes e eficazes) sugere que a desregulamentação não é caracterizada apenas pela redução da quantidade de normas e regras, mas, também, pela substituição delas por outras com viés menos intervencionista ${ }^{(6)}$ Esse processo de substituição pode ser denominado de "re-regulação" ou "reforma regulatória". Desregulação ou desregulamentação, assinala Krajewski, "refere-se à redução ou eliminação da regulação, enquanto re-regulação ou re-regulamentação significa a introdução de novas regras em área já desregulada ou desregulamentada". Na prática, contudo, esses processos coincidem com muita frequência. ${ }^{(7)}$

De qualquer modo, constitui a desregulação ou desregulamentação processo intimamente relacionado a políticas de liberalização. É estimulado ou promovido por "setores vinculados ao sistema capitalista transnacional", para usar expressão de José Eduardo Faria, que, por disporem de condições

de atuar na "economia-mundo", pressionam o Estado a melhorar e ampliar as condições de "competitividade sistêmica". Entre outras pretensões, eles reivindicam a eliminação dos entraves que bloqueiam a abertura comercial, a desregulamentação dos mercados, a adoção dos programas de desestatização, a "flexibilização" da legislação trabalhista e a implantação de outros projetos de "deslegalização" e "desconstitucionalização"."(s)

Se, de um lado, a redução de normas e regras, muitas vezes, propicia maior abertura de mercado e ampliação das condições de "competitividade sistêmica", de outro, sua abolição não conduz necessariamente ao estabelecimento de concorrência efetiva, especialmente em um contexto de privatização. Além disso, a pura desregulamentação frequentemente implica não somente maiores dificuldades de acesso a serviços essenciais (i. e., com preços bem acima do poder aquisitivo da maioria da população) como também distribuição desigual de renda e riqueza (KRAJEWSKI, 2003. p. 8).

Já a privatização, como observa Cristiane Derani, consiste na transferência de um serviço realizado pelo poder público para o poder privado e também na transferência da propriedade de bens de produção públicos para o agente econômico privado. Pela primeira modalidade, diz ela, "a titularidade do serviço continua sendo do poder público, mas seu exercício é transferido para o agente privado". Outro modo de transferência do poder público ao poder privado caracteriza-se pela venda de ativos pelo Estado, com sua consequente retirada da atividade produtiva que desempenhava ${ }^{(9)}$

(6) Para Fernando Herren Aguillar (2006. p. 209), a desregulamentação "é apenas uma nova forma de regulação... e não menos política do que qualquer regulação normativa concentrada. E assim é também porque a desregulamentação é patrocinada pelo Estado, que escolhe, circunstancialmente, omitir-se em determinados segmentos da vida social e, ao fazê-lo, permite que tais setores sejam controlados por outrem. Trata-se de uma desconcentração regulatória normativa em seu grau mais elevado".

(7) ("Deregulation refers to the reduction or elimination of regulation, while re-regulation means the introduction of new regulations in a deregulated area.") (KRAJEWSKI, 2003. p. 8).

(8) Ver Faria (1999. p. 25-26).

(9) No tocante à transferência do exercício de atividade do setor de serviços para o agente privado, a autora apoia-se no art. 175 da Constituição Federal, que dispõe: "Incumbe ao Poder Público, na forma da lei, diretamente ou sob regime de concessão ou permissão, sempre através de licitação, a prestação de serviços públicos" (DERANI, 2002. p. 110). 
No setor de serviços, o processo de privatização deve inserir-se em um contexto de política econômica geral desenhada por autoridades governamentais, cuja eficácia depende, em larga medida, de reformas ou ajustes regulatórios que assegurem o estabelecimento e a manutenção da concorrência, bem como o acesso universal àqueles considerados essenciais. São justamente essas condições ou esses requisitos de eficácia que aproximam, na prática, as políticas de liberalização e de privatização.

\section{BUILT IN AGENDA DO GATS: ESPAÇO PARA RECALIBRAÇ̃̃o DE PRIORIDADES E VALORES}

Referências às necessidades específicas dos PED e dos países de menor desenvolvimento econômico (Least Developed Countries - LDC) permeiam boa parte dos acordos que compõem a OMC. Nos termos do parágrafo segundo do Preâmbulo de seu Acordo Constitutivo, um dos objetivos da OMC é

(o) de realizar esforços positivos para que os países em desenvolvimento, especialmente os de menor desenvolvimento econômico relativo, obtenham uma parte do incremento do comércio internacional que corresponda às necessidades de seu desenvolvimento econômico.

O art. 66 do Trade Related Intellectual Property Rights - TRIPS, por exemplo, isenta os LDC do cumprimento de certas obrigações, durante determinado período, em "virtude de suas necessidades e requisitos especiais, de suas limitações econômicas, financeiras e administrativas e de sua necessidade de flexibilidade para estabelecer uma base tecnológica viável...". O próprio GATS, em seu art. IV, estabelece que a "participação crescente dos países em desenvolvimento no comércio mundial será facilitada mediante compromissos específicos negociados pelos diferentes membros...".

Apesar disso, não há dúvidas de que, como assinalam Hoekman et al. (2004),

em larga medida, as regras da OMC refletem os "interesses" dos países ricos: elas são menos rigorosas no tocante a políticas de distorção favorecidas por esses países, além de espelharem amplamente as (best practice) disciplinas que ao longo do tempo por eles foram postas em vigor.

Assim, prosseguem eles,

a latitude muito maior que existe na $\mathrm{OMC}$ para o uso de subsídios à agricultura, por exemplo, reflete o uso de tais políticas de apoio em muitos países em desenvolvimento. O mesmo é verdade no que se refere ao enfoque permissivo que, historicamente, eles têm adotado no uso de quotas de importação sobre os produtos têxteis — o que, em princípio, foi proibido pelas regras do GATT. Mais recentemente, a inclusão de regras de proteção aos direitos de propriedade intelectual tem levado à percepção de que o contrato da OMC continua desequilibrado. ${ }^{(10)}$

(10) Ver a respeito: Hoekman, Michalopoulos, Winters (2004. p. 482) ((To) "a significant extent WTO rules reflect the 'interests' of rich countries: they are less demanding about distortionary policies that are favoured by these countries and they largely mirror the ('best practice') disciplines that have over time been put in place by them". (Thus) "the much 
Esse desequilíbrio da OMC, na visão de Rabih Nasser, é reflexo da ideologia econômica liberal que predomina no sistema multilateral de comércio. Para ele,

(a regulação de) diversos temas como propriedade intelectual, comércio de serviços, subsídios, consolidação de patamares máximos para tarifas de importação aplicáveis ao comércio de bens tem por objetivo impedir que os participantes do sistema ajam de forma incompatível com os predicados dessa ideologia econômica, mesmo que haja a percepção internamente de que é necessário para o desenvolvimento.

Em consequência, assinala o autor, "as opções de que dispõem os países em desenvolvimento no que se refere à promoção de políticas de desenvolvimento são reduzidas pelo disposto nesse regime jurídico, que delineia os princípios que devem ser observados por todos".

A conclusão a que chega Nasser é a de que as restrições à liberdade dos países de adotarem políticas de incentivo ao desenvolvimento têm o efeito de perpetuar uma situação de desequilíbrio nos níveis de desenvolvimento dos países integrantes do sistema multilateral de comércio. Esse resultado é diametralmente oposto ao objetivo traçado no Acordo Constitutivo da OMC de que "os países em desenvolvimento, especialmente os de menor desenvolvimento relativo, obtenham uma parte do incremento do comércio internacional que corresponda às necessidades de seu desenvolvimento econômico" (NASSER, 2003, p. 84-113).

A OMC, na realidade, tem funcionado de modo inconsistente com seu próprio mandato. Assegurar o pleno emprego e aumentar padrões de vida certamente não constituem referências ou padrões de avaliação dos países desenvolvidos quando pressionam a agenda das negociações na Rodada Doha. O sistema tem operado, portanto, com base na crença de que os princípios (neo) liberais serão de facto a melhor política de desenvolvimento para os PED, enquanto os próprios países desenvolvidos buscam o maior número possível de alternativas para proteger seus setores sensíveis. Como diz Aileen Kwa, o sistema "não optou por refletir acerca da agora clara evidência empírica das falhas das políticas neoliberais e, portanto, não permitiu uma recalibração de suas prioridades, seus valores e seus modos de funcionamento". ${ }^{(11)}$

A recalibração das prioridades, dos valores e dos modos de funcionamento do sistema multilateral implicaria a efetiva inclusão de temas relacionados a questões sociais e de desenvolvimento, que não podem ser dissociados do objetivo de liberalização do comércio internacional. Essa recalibração é necessária como forma de corrigir ou, pelo menos, diminuir o desequilíbrio operacional do sistema em favor dos países desenvolvidos.

greater latitude that exists in the WTO for the use of agricultural subsidization, for example, reflects the use of such support policies in many developed countries. The same is true for the permissive approach that has historically been taken towards the use of import quotas on textile products - which in principle was prohibited by GATT rules. More recently, the inclusion of rules on the protection of intellectual property rights has led to perceptions that the WTO contract continues to be unbalanced".) Em outro texto sobre o assunto, Hoekman ressalta que, no "final dos anos 90, muitos países tinham chegado à conclusão de que a OMC estava desequilibrada, o que refletia, inter alia, numerosos problemas e questões relacionados à implementação". ((By) "the end of the 1990s many countries had come to the view that the WTO was unbalanced, reflected, inter alia, innumerous implementation - related issues and concerns".) (HOEKMAN, 2005. p. 410).

(11) ((The system) "has not chosen to reflect on the now clear empirical evidence of the failures of neo-liberal policies, and has not accordingly allowed itself to recalibrate its priorities, values and ways of functioning".) (KWA, 2007. p. 28). 
É fato que as opções de que dispõem os PED no que se refere à promoção de políticas de desenvolvimento foram reduzidas pelo disposto no regime jurídico da OMC. As normas da OMC limitaram, com maior ou menor intensidade, a flexibilidade dos membros quanto à escolha dos instrumentos que podem ser usados na implantação de objetivos de políticas de desenvolvimento. Quando não limitaram expressamente, deixaram em aberto essa possibilidade, qual seja, a de restrição do direito dos membros de regular ou legislar, ou, posto de outra forma, de fazer políticas públicas (policy space) como muitos dos membros, sobretudo os desenvolvidos, fizeram no passado.

Essa limitação aparece com maior clareza nos acordos TRIPS, Trade Related Investment Measures (TRIMS) e Subsidies and Countervailing Measures (SCM), dentre outros. Nesse tocante, Howse e Teitel assinalam que vários dos acordos que compõem a OMC

contêm restrições à capacidade dos membros (da $\mathrm{OMC}$ ) de usar instrumentos de política interna, seja no caso de licença compulsória, no caso do TRIPS, subsídios para alimentos, no caso do Acordo de Subsídios e Medidas Compensatórias (SCM), e no Acordo sobre Agricultura, ou no que respeita medidas de política industrial, tais como exigências de conteúdo local. ${ }^{(12)}$

No caso do TRIPS, as limitações contidas em seu art. $8^{\circ}$, no tocante à adoção de medidas "necessárias para proteger a saúde e nutrição públicas e para promover o interesse público em setores de importância vital para seu (dos membros) desenvolvimento socioeconômico e tecnológico...", quase provocaram um contencioso entre Brasil e Estados Unidos na OMC. O governo brasileiro, em relação ao disposto no art. 71 de sua Lei de Propriedade Industrial (Lei n. 9.279, de 14 de maio de 1996), cogitou outorgar licença compulsória para exploração da patente de certos medicamentos de combate à AIDS. Os Estados Unidos, pressionados por poderosos conglomerados da indústria farmacêutica, reagiram com veemência, sob a alegação de que tal medida seria contrária às disposições do art. $8^{\circ}$ do TRIPS. ${ }^{(13)}$

No entanto, a Declaração de Doha de 2001 sobre o TRIPS e Saúde Pública enfatizou que o Acordo deverá ser interpretado e implementado de tal modo a garantir a proteção da saúde pública e a promoção de amplo acesso a medicamentos nos membros. Segundo assinala Maristela Basso, a Declaração vai além da mera interpretação do art. $8^{\circ}$, "quando apresenta interpretação extensiva de garantia pelos estados-membros com relação aos objetivos do

(12) Ver Howse e Teitel (2007.p. 12) ((Various WTO treaties) "contain constraints on the ability of WTO Members to use domestic policy instruments, whether compulsory licensing in the case of TRIPS, subsidies including food subsidies in the case of Subsidies and Countervailing Measures (SCM) Agreement and the Agreement on Agriculture, or industrial policy measures such as local content requirements".)

(13) Estabelece o art. 71 da Lei de Propriedade Industrial Brasileira: "Nos casos de emergência nacional ou interesse público, declarados em ato do Poder Executivo Federal, desde que o titular da patente ou seu licenciado não atenda a essa necessidade, poderá ser concedida, de ofício, licença compulsória, temporária e não exclusiva, para a exploração da patente, sem prejuízo dos direitos do respectivo titular". Já o art. $8^{\circ}$ do TRIPS prevê: "1. Os membros, ao formular ou emendar suas leis e regulamentos, podem adotar medidas necessárias para proteger a saúde e nutrição públicas e para promover o interesse público em setores de importância vital para seu desenvolvimento socioeconômico e tecnológico, desde que essas medidas sejam compatíveis com o disposto neste Acordo. 2. Desde que compatíveis com o disposto neste Acordo, poderão ser necessárias medidas apropriadas para evitar o abuso dos direitos de propriedade intelectual por seus titulares ou para evitar o recurso a práticas que limitem de maneira injustificável o comércio ou que afetem adversamente a transferência internacional de tecnologia”. 
TRIPS relacionados à saúde pública" (BASSO, 2008, p. 75). ${ }^{(14)}$ A Declaração acabou reforçando a tese do Brasil segundo a qual questões de saúde pública não se subordinam ao TRIPS, o que, de certa forma, desestimulou o governo norte-americano a iniciar processo contencioso na $\mathrm{OMC}$, de resto desnecessário, até porque o Brasil, à época, não chegou a decretar o licenciamento compulsório de patente.

Seja como for, o caso é ilustrativo do conflito potencial entre a capacidade dos membros de adotar políticas públicas e as normas do TRIPS. O TRIPS é mais restritivo ainda no que se refere à possibilidade de transferência de tecnologia aos países em desenvolvimento, como observado em relatório da Comissão de Direitos Humanos da ONU:

Conceder jurisdição internacional à OMC sobre TRIPS restringiria, não liberalizaria, direitos de propriedade intelectual. Esse processo irá criar provavelmente monopólios globais que irão beneficiar corporações transnacionais em detrimento do interesse público. A proteção aos direitos de propriedade intelectual tornará impossível a disseminação da informação sobre a produção de invenções, mesmo nas áreas relativas a tecnologias aparentemente comprometidas com a ecologia e saúde..$^{(15)}$

O Acordo TRIMS não define medidas de investimentos relacionadas ao comércio. Fornece apenas no Anexo I uma lista ilustrativa de medidas que, nos termos do $\S 2^{\circ}$, do art. $2^{\circ}$, são incompatíveis com a obrigação de conferir tratamento nacional consignada no $\S 4^{\circ}$, do art. III, e com a obrigação de eliminação geral das restrições quantitativas previstas no $\S 1^{\circ}$, do art. XI, do GATT, a saber: (i) exigência de aquisição pelo investidor de produtos locais na produção (conteúdo local); (ii) limitação das importações a um porcentual das exportações; (iii) restrições ao acesso de divisas estrangeiras e a importações; e (iv) imposição de metas ou compromissos de exportação (desempenho exportador). ${ }^{(16)}$

Carreau e Juillard extraem duas consequências dessa lista ilustrativa. De um lado, dizem eles,

a escolha de ilustrações que confere a lista indicativa parece indicar que o acordo condena apenas as MIC (medidas de investimento relacionadas ao comércio) por ele enumeradas, já que são as únicas incompatíveis com os arts. III:4 e XI:1. De outro, porém, essas ilustrações não são mais do que ilustrações e elas não prejulgam, portanto,

(14) ((The Doha Declaration on TRIPS and Public Health, of 2001, goes beyond the mere reiteration of articles 7 and 8 of the TRIPS) "when it presents an extensively guaranteed interpretation by the Member States with regards to the objectives of the TRIPS concerning public health".) (BASSO, 2008. p. 75).

(15) ("Granting WTO international jurisdiction over TRIPs would restrict, not liberalize, intellectual property rights. This process is likely to create global monopolies beneficial to TNCs (corporações transnacionais) at the cost of public interest. The protection of intellectual property rights would render impossible the dissemination of information on the production of new inventions, even in the area of ecologically sound technologies and health".) Comissão de Direitos Humanos da ONU. Relatório do Secretário-Geral. "The Realization of Economic, Social and Cultural Rights. The impact of the activities and working methods of transnational corporations on the full enjoyment of all human rights, in particular economic, social and cultural rights and the right to development, bearing in mind existing international guidelines, rules and standards related to the subject matter." E/CNSub.2/1996. p. 69 c), apud Perrone-Moisés (1998. p. 41).

(16) A esse respeito expõe Vera Thorstensen (2001. p. 102-103) que: "as políticas dos governos normalmente incluem incentivos e fornecimento de bens ou serviços em termos preferenciais. Em troca, exigem o cumprimento de certo número de regras como a de conteúdo local, isto é, a compra de partes e componentes de fabricação doméstica, ou a de desempenho exportador, isto é, o compromisso de exportar parte dos bens produzidos. Podem também exigir transferência de tecnologia, capital mínimo nacional ou joint venture". (grifos no original) 
qual seria a posição das instâncias da OMC vis-à-vis outras MIC que poderiam, elas também, se colocar como incompatíveis seja com o art. III ou com o art. XI:I. ${ }^{(17)}$

Muito embora tenha sido conferida aos PED a possibilidade de deixar de aplicar temporariamente os dispositivos do Acordo TRIMS nos casos relacionados a problemas na balança de pagamentos ou em relação à necessidade de proteção a indústrias emergentes, não se pode negar que seu espaço para utilização desse importante instrumento de promoção de desenvolvimento industrial, que são as medidas de investimento relacionadas ao comércio, foi drasticamente reduzido. Além disso, é preciso lembrar que não há no Acordo TRIMS qualquer dispositivo regulamentando a conduta de empresas transnacionais ou multinacionais, cujas atividades podem, muitas vezes, ferir interesses econômicos locais. Por exemplo: quando a matriz proíbe a subsidiária de exportar porque decide privilegiar fontes de produção em outros países dentro de uma estratégia global de produção, mesmo quando a subsidiária dispõe de todas as vantagens comparativas para exportar.

Para PED, como o Brasil e seus parceiros do Mercosul, a possibilidade de exigir desempenho exportador e conteúdo local continua sendo importante, como, de resto, o foi para os atuais países desenvolvidos há algumas décadas. ${ }^{(18)}$ Há algum tempo, o governo brasileiro encomendou alguns estudos para o estabelecimento de uma política de implantação da TV digital no país. Nesses estudos figuraram algumas propostas de adoção de offsets ou contrapartidas, como a exigência de aquisição de conteúdo local para a fabricação de componentes para TV digital. Se essa política (que não deixa de ser política industrial) tivesse sido implantada nesses moldes, o Brasil poderia ter enfrentado alguns questionamentos na OMC quanto à sua inconsistência vis-à-vis o Acordo TRIMS.

Por essa razão, o Brasil vem há muito tempo defendendo a necessidade de flexibilização dessas regras do Acordo TRIMS, de forma a poder adotar medidas de investimento relacionadas ao comércio e impulsionar seu desenvolvimento. Em 2002, o país apresentou com a Índia proposta de modificação dessas regras, que contou ainda com o apoio da Argentina, da Colômbia e do Paquistão, dentre outros. Brasil e Índia basearam-se em estudos da própria OMC e da UNCTAD que mostravam que as TRIMS haviam sido importantes para os países ricos nas fases iniciais de desenvolvimento.

Ao defender a flexibilização do Acordo TRIMS, o então embaixador do Brasil junto à $\mathrm{OMC}$, Felipe Seixas Corrêa,

argumentou que o grande problema na implementação de TRIMS é que suas regras são impostas a todos da mesma maneira, sem distinguir o estágio de desenvolvimento de cada país. Assim, as enormes disparidades tecnológicas, sociais, regionais e

(17) (..." le choix des illustrations que donne la liste indicative semble indiquer que l'accord ne condamne que les seules MIC (medidas de investimento relacionadas ao comércio) qu'il énumère, parce que ce sont les seules qui s'avèraient incompatibles avec les arts. III:4 et XI:1. Mais d'autre part, ces illustrations ne sont jamais que des illustrations, et elles ne préjugent donc pas de ce que serait la position des instances de l'OMC vis-à-vis d'autres MIC qui pourraient, elles aussi, s'avèrer incompatibles avec l'art. III: ou avec l'art. XI:1"). Cf. Carreau e Juillard (1998. p. 178-179).

(18) O Canadá, o Japão e a Coreia do Sul fizeram uso constante dessas medidas de política industrial. A Coreia do Sul, aliás, pode-se dizer, "abusou" dessas medidas para montar seu parque automotivo. Também o Brasil utilizou-se dessas medidas por meio do Befiex, mecanismo usado nas décadas de 1970 e 1980 para induzir companhias nacionais e estrangeiras a exportar parte de sua produção relativa ao que importavam. 
ambientais entre os países "tornam difícil, senão impossível, para o Acordo de TRIMS gerar benefícios equilibrados para todos". ${ }^{(19)}$

Essa proposta apresentada por Brasil e Índia tem, dentre seus objetivos, alterar o Acordo TRIMS para: (i) promover a indústria doméstica com alto valor agregado; (ii) estimular transferência de tecnologia; (iii) aumentar a capacidade de exportação; (iv) promover pequenas e médias empresas e gerar empregos. ${ }^{(20)}$

Quanto ao Acordo SCM, o caso Brasil (Embraer) v. Canadá (Bombardier) constitui exemplo eloquente da diminuição do espaço para a implantação de políticas comerciais de estímulo à exportação. ${ }^{(21)}$

O caso teve início quando, em meados da década de 1990, se implantavam no Brasil alguns dos princípios do "Consenso de Washington", apoiados à época pelos países desenvolvidos, como o Canadá. Após bem-sucedido processo de privatização, a Embraer tornou-se uma empresa bem mais competitiva, mas, ainda assim, precisava de algum tipo de apoio governamental para poder concorrer em melhores condições com os grandes players do mercado de aviões de médio porte. Com os incentivos recebidos por meio de um programa de exportação do governo brasileiro denominado PROEX, a Embraer venceu, em 1996, uma concorrência internacional para a venda de um número significativo de aeronaves para companhias aéreas dos Estados Unidos. A grande derrotada nessa concorrência foi a canadense Bombardier, detentora na ocasião de mais de 50\% do mercado mundial dessas aeronaves de porte médio.

Inconformada com a derrota, afinal o valor da concorrência atingia a cifra de aproximadamente 4 bilhões de dólares, a Bombardier pressionou o governo canadense a iniciar consultas junto ao governo brasileiro, com o objetivo de apurar se, de fato, como alegava a empresa canadense, a Embraer havia recebido subsídios governamentais do tipo "apoio à exportação". O governo brasileiro negou que tivesse concedido qualquer forma de subsídio contrária às regras da $\mathrm{OMC}$, previstas no $\mathrm{SCM}$.

O Canadá não aceitou os argumentos apresentados pelo Brasil e, em conformidade com as disposições do Entendimento sobre Solução de Controvérsias (Anexo 2 do Acordo da $\mathrm{OMC}$ ), requisitou a instalação de um Painel para analisar o caso. Para o governo canadense, o PROEX constituía um subsídio vedado pelo SCM, já que funcionava como um indisfarçável e direto incentivo às exportações da Embraer. Ainda que houvesse no SCM previsão para tratamento especial a países emergentes, ou seja, a possibilidade de, em algumas situações, tais países adotarem instrumentos de políticas de desenvolvimento, o Brasil, na visão canadense, não poderia se beneficiar desse mecanismo, pois havia concedido subvenção de valor expressivo, isto é, muito superior ao limite normalmente aceitável.

O Brasil, em sua defesa, não contestou se o PROEX seria um tipo de subsídio. Um subsídio, porém, perfeitamente de acordo com o SCM para um país em desenvolvimento.

\footnotetext{
(19) Ver jornal Gazeta Mercantil de 15.10.2002. p. A-6.

(20) Nesse tocante, ver Celli Junior (2005. p. 81-96), artigo também publicado em Basso (2007. p. 533-546). Ver também de Celli Júnior (2007. p. 355-371; 2006. p. 37-52; 2004. p. 505-521).

(21) Brazil - Export Financing Program for Aircraft (WT/DS46). Disponível em: <http://www.wto.org > Acesso em: 14.11 .2006 
Em linhas gerais, o PROEX consistia em um programa de equalização das taxas de juros cobradas por instituições financeiras internacionais em contratos de financiamento à importação de produtos de países emergentes, em virtude de seus riscos e das instabilidades políticas e econômicas. Assim, por exemplo, companhias aéreas interessadas em importar aviões de uma empresa de país desenvolvido, como a Suécia, ao buscarem financiamentos internacionais, com o apoio e a intermediação da empresa exportadora, pagariam taxas de juros comparativamente baixas, uma vez que a Suécia é um país de risco próximo a zero. De outro lado, a taxa de juros para o financiamento à importação cobrada dessas mesmas companhias aéreas, caso desejassem importar aviões de um país emergente, como o Brasil, seria muito mais elevada, devido ao denominado "risco-país".

No caso específico da concorrência internacional vencida pela Embraer, essa conseguiu apresentar um "pacote de financiamento" bastante atrativo para as companhias aéreas dos Estados Unidos. Como se tratava de financiamento de importação para aquisição de bens de um país menos estável como o Brasil, as instituições financeiras cobrariam, como de praxe, taxas de juros mais elevadas. Pelo mecanismo de equalização, o governo brasileiro comprometia-se a cobrir essa diferença na taxa de juros. Imagine-se que, para o financiamento concedido a importações de aviões da Bombardier, do Canadá, a taxa de juros cobrada fosse de $2 \%$ e que para o mesmo tipo de financiamento concedido a importações de aviões da Embraer a taxa de juros fosse de $10 \%$. A diferença de $8 \%$ seria coberta pelo governo brasileiro.

O Brasil sustentou, portanto, que a equalização visava tão somente a corrigir uma distorção de mercado que levava uma empresa de país desenvolvido a ficar em condições artificialmente mais competitivas. Tratava-se, pois, de subsídio especial, cuja concessão era permitida para países emergentes nos termos do SCM.

O Painel da OMC não entendeu desse modo. De acordo com seu relatório, apresentado ao OSC e distribuído às partes, o subsídio do PROEX era inconsistente com o SCM, isto é, tratava-se de subsídio ilegal em relação aos dispositivos do SCM. ${ }^{(22)}$ Como era de esperar, o Brasil recorreu ao Órgão de Apelação, o qual, essencialmente, ratificou o teor do relatório do Painel. O Brasil teria, portanto, de retirar os subsídios concedidos via PROEX, sob pena de o OSC vir a autorizar o governo canadense a adotar medidas compensatórias contra o Brasil. Como deixou de cumprir a determinação daquele Órgão, este autorizou o Canadá a adotar medidas compensatórias contra o Brasil, no montante aproximado de 3,6 bilhões de dólares. ${ }^{(23)}$

\footnotetext{
(22) Mais especificamente, em face do art. $3^{\circ}, 1$ (a), nos termos do qual: "Com exceção do disposto no Acordo sobre Agricultura, serão proibidos os seguintes subsídios, conforme definidos no art. $1^{\circ}$ : (a) subsídios vinculados, de fato ou de direito, ao desempenho exportador, quer individualmente, quer como parte de um conjunto de condições, inclusive aqueles indicados a título de ex emplo no Anexo I;" Um dos exemplos dessa lista ilustrativa do Anexo I é "(a) A concessão pelos governos de subsídios diretos à empresa ou à produção, fazendo-os depender do desempenho exportador".

(23) Cf. Celli Junior (2007). No segundo caso envolvendo os dois países, ficou comprovado que o Canadá também havia concedido à Bombardier subsídios inconsistentes com o SCM. O Brasil foi autorizado a adotar medidas compensatórias contra o Canadá. O valor relativamente irrisório de 270 milhões de dólares é o que menos conta. O que teve importância mesmo foi o caráter simbólico da vitória. Foi possível demonstrar, pela primeira vez de modo efetivo, que países emergentes como o Brasil podem utilizar em seu benefício o mecanismo de solução de controvérsias da OMC, ainda que isso contrarie interesses de países desenvolvidos. Os subsequentes sucessos do Brasil nos casos do açúcar e do algodão são exemplos disso.
} 
Se, de um lado, as opções de que dispõem os PED no que se refere à promoção de políticas de desenvolvimento foram reduzidas pelo disposto no regime jurídico da OMC, de outro, também é certo que, tendo em vista o próprio mandato ou os objetivos da organização (ver parágrafo do Preâmbulo do Ato Constitutivo descrito acima), existe a possibilidade da reafirmação ou manutenção da capacidade dos membros de implantar políticas de desenvolvimento dentro desse mesmo regime ou sistema. A característica de built in agenda do GATS, ao conferir maior espaço para recalibração de prioridades, valores e modos de funcionamento da OMC, permite o exercício dessa possibilidade. ${ }^{(24)}$

A recalibração do sistema e a consequente reafirmação do espaço para a implantação de políticas públicas pelos membros, sobretudo no âmbito do GATS, encontram respaldo naquilo que Lafer, com base em Grócio, descreve como "potencial de sociabilidade e solidariedade na esfera internacional". Esse potencial, lembra Celso Lafer,

provê - e este é o pressuposto no qual se fundamenta a $\mathrm{OMC}$ - uma interação organizada e não anárquica entre os atores da vida econômica num mercado globalizado, que não funciona como um jogo de soma zero, em que o ganho de um significa a perda de outro. Há conflito, mas também há cooperação, lastreada num processo abrangente que tem sua base na racionalidade e na funcionalidade da reciprocidade de interesses (LAFER, 1998. p. 28).

É esse espaço para cooperação que PED, como o Brasil, devem ocupar. O equilíbrio de forças, que resultou na fórmula-compromisso do GATS, é exemplo da "racionalidade e funcionalidade da reciprocidade" de interesses a que alude Lafer. O papel catalisador que vem exercendo o G-20 nas negociações da Rodada Doha também é ilustrativo da viabilidade da recalibração de prioridades, valores e modos de funcionamento da OMC.

Na diplomacia e na política, lembra Luiz Olavo Baptista, "o simbólico tem valor, às vezes, maior do que o fato. Ainda que não se tenha exercido diretamente o poder, a reserva de vir a exercê-lo em algum momento no futuro tem valor simbólico que é ultrapassado e pode chegar à efetividade concreta" (BAPTISTA, 2007. p. 17). Essa efetividade concreta, assegurada pelas relevantes funções que os Painéis e o Órgão de Apelação desempenham ao determinar qual a interpretação correta e como a regra se aplica aos fatos, é mais uma indicação de que os PED podem e devem exercer essa reserva de poder a que se refere Baptista para reafirmar ou manter sua capacidade (policy space) de implantar políticas de desenvolvimento via regulação.

Em anos recentes, a arguição feita por alguns PED em foros multilaterais em favor da reafirmação ou manutenção do policy space tem sido combatida com veemência sobretudo por alguns economistas liberais mais ortodoxos que se recusam a admitir que a abertura comercial não foi suficiente para o desenvolvimento e a diminuição da pobreza. Segundo assinalam Corrales, Sugathan e Primack,

\footnotetext{
(24) Quanto ao fato de o GATS constituir uma built in agenda, diz Pierre Sauvé: "O fato de o GATS dever ser visto como um trabalho em progressão não constitui surpresa quando é examinado à luz da notável diversidade de atividades por ele abrangidas e da velocidade com que o desenvolvimento de tecnologias e de enfoques regulatórios afeta a política e a elaboração de regras para o setor". "That the GATS should be seen as work in progress is hardly surprising when viewed in light of the remarkable diversity of activities it encompasses and the rapid pace at which developments in technology and regulatory approaches affect policy-and-rule-making in the sector") (SAUVÉ, 2002. p. 304).
} 
(o) modelo ortodoxo de liberalização comercial parece ter eclipsado muitas das perspectivas dos países em desenvolvimento sobre como fazer uso efetivo desses espaços (como no caso de muitos LDCs que retêm um amplo grau de autonomia), bem assim como as regras do comércio internacional afetam tais espaços. ${ }^{(25)}$

Como referido anteriormente, para os defensores do modelo ortodoxo de liberalização comercial, o encolhimento do espaço político para os governos dos PED na área de políticas comerciais (e industriais) é, de fato, algo bom, pois evita que esses países cometam erros ao adotarem políticas onerosas, seja por crenças enganosas no intervencionismo ou devido às políticas de grupos de interesse.

A (re) introdução na agenda multilateral e, em particular, na built in agenda do GATS, do tema relacionado à necessidade de manutenção do espaço para adotar políticas públicas e de regulação voltadas para o desenvolvimento não constitui, como querem fazer crer esses economistas, um retrocesso ou a retomada de um protecionismo nos moldes de algumas décadas atrás. Trata-se de uma forma de corrigir e, no caso do GATS, de prevenir falhas de políticas neoliberais recentes que não levaram ao desenvolvimento e à redução das assimetrias entre os membros da OMC.

Sob o GATS, isso é possível, até porque é pouco substancial o nível de comprometimento dos membros até o presente. Como lembram Howse e Teitel (2007),

os membros da OMC podem vir a assumir compromissos no GATS para liberalizar o acesso a mercados em setores relacionados a serviços essenciais, tais como saúde e água, limitando, de modo significativo, sua capacidade de impor objetivos públicos pertinentes às dimensões de segurança humana dos direitos sociais e econômicos (como acesso universal à água tratada) sobre operadores econômicos privados que têm direito de participar no mercado de acordo com os compromissos assumidos sob o GATS.

Até o momento, dizem eles,

foram poucos os compromissos negociados que afetam diretamente esses serviços públicos; na atual rodada de negociações, ativistas de ONGs têm contribuído para aumentar o grau de conscientização sobre os riscos para o policy space e os direitos humanos de se aceitarem as solicitações de alguns membros da OMC de garantia de acesso a mercados nessas áreas. ${ }^{(26)}$

De fato, esse risco existe. Se, de um lado, alguns elementos do GATS parecem ser sensíveis à necessidade de regulação nacional e flexíveis o suficiente para permitir um "espaço regulador", de outro, o Acordo também contém certos dispositivos que são

(25) Ver Corrales-Leal, Sugathan e Primack (2003. p. 4).

(26) ((In addition, "WTO Members could bind themselves under the General Agreement on Trade in Services (GATS) to liberalize market access in sectors related to essential services, such as health care and water, limiting in important ways their ability to impose public goals related to the human security dimensions of economic and social rights (such as universal affordable access to clean water) on private economic operators who have a right to participate in the market under the GATS commitments".) ((So far), "their have been few commitments negotiated that directly affect such public services; in the current round of negotiations, NGO activists have effectively raised awareness of the risks to policy space, and to human rights, of acceding to demands of some WTO Members for guaranteed market access in these areas"). (HOWSE, TEITEL, 2007. p. 12). 
claramente destinados a disciplinar (i.e., restringir) a regulação nacional e limitar a autonomia reguladora ou legislativa dos membros.

Além disso, a existência de numerosos dispositivos ambíguos, pouco claros e muito abrangentes pode ser usada para interpretar o GATS de tal forma a inserir-lhe limites ainda maiores às opções de regulação interna ou nacional. O atual quadro político e ideológico do regime internacional de comércio ainda parece particularmente receptivo a tentativas de se limitar o amplo uso de flexibilidade e abertura do GATS. Dá́, mais uma vez, a importância da recalibração de prioridades, valores e modos de funcionamento da OMC, bem como, e particularmente, da reafirmação do policy space e da autonomia reguladora dos membros no GATS.

\section{REAFIRMAÇão DO POLICY SPACE PARA O DESENVOLVIMENTO: IMPLICAÇÕES PARA O GATS}

Nas últimas duas décadas, intensificou-se no sistema multilateral um movimento progressivo de substituição do papel de uma estratégia de desenvolvimento pelo de uma estratégia de liberalização. Com a consolidação desse movimento, o nexo causal entre liberalização e desenvolvimento passou a ser feito de forma automática. Como resultado, virou prática comum em vários países, especialmente nos $\mathrm{PED}$, a adoção de pacote de políticas que viam o processo de liberalização como um fim em si mesmo, em vez de um meio para alcançar o desenvolvimento. ${ }^{(27)}$

Esse pacote de políticas que, mais tarde, viria a ser conhecido como o "Consenso de Washington" apregoava a liberalização comercial e financeira, a estabilidade macroeconômica e mínima intervenção governamental na economia. Isso levou a um crescente avanço das regras do sistema multilateral sobre a autonomia da política econômica interna dos membros, ou seja, conduziu a uma efetiva proibição do uso de muitos dos instrumentos que tinham possibilitado muitos países em passado recente, como alguns países asiáticos, a implantar a integração comercial de forma estratégica.

Aliás, grande parte do sucesso da economia dos denominados Tigres Asiáticos pode ser atribuída à intervenção de seus governos na economia, especialmente com relação ao uso combinado de políticas industriais tradicionais e de políticas de capacitação tecnológica. Em vez de seguirem o receituário de estratégia de liberalização comercial abrangente, esses países puderam empregar, em um cenário de relativa autonomia de implantação de

(27) Paradoxalmente, porém, lembram Corrales-Leal et al. (2003), a justificativa para esse abrangente pacote de políticas de liberalização "decorreu das histórias de sucesso de várias economias de países asiáticos que seguiram uma "integração comercial estratégica” (strategic trade integration), que confiou pesadamente em políticas de intervenção na economia, especialmente na área de fornecimento". ((Paradoxically, however) "the justification for this comprehensive package of liberalisation policies came from the success stories of several Asian economies that followed a 'strategic trade integration', which relied heavily on policy interventions in the economy, especially on the supply-side”). Para eles, strategic trade integration "constitui o processo de aumento da participação de um país nos mercados mundiais pelo uso de políticas ativas voltadas para a melhoria da competitividade e a otimização da sequência da liberalização da exportação e da importação de acordo com as metas de desenvolvimento sustentável de cada país”. ((By 'strategic trade integration') “we refer to the process of increasing a country's participation in world markets by making use of active policies to improve competitiveness and optimizing the sequencing of export \& import liberalisation according to a country's own sustainable development goals".) (CORRALES-LEAL, 2003. p. 3 e nota 2 da mesma página). 
políticas públicas, um bem-definido enfoque de integração comercial, por meio do qual selecionaram medidas do pacote de liberalização que lhes pareceram mais vantajosas, deixando de lado outras não consideradas benéficas.

A adoção desse pacote de políticas do "Consenso de Washington" pelos PED impediu-os, em grande medida, de romper com as condições de pobreza neles predominantes. A estratégia de desenvolvimento baseada exclusivamente na estabilidade macroeconômica e na liberalização comercial e financeira não gerou desenvolvimento e crescimento econômico sustentáveis na grande maioria deles. Isso não significa, é claro, que a liberalização per se tenha sido responsável pela continuidade das condições de pobreza predominantes, mas que alguns elementos importantes deixaram de constar desse pacote de políticas. É por isso que, como salientam Corrales-Leal et al., se os PED quiserem reverter essa tendência, "os termos nos quais esse processo de liberalização tem sido implementado - em especial as características de desenvolvimento do sistema multilateral em que ele opera — precisam ser revisitados". ${ }^{(2 s)}$

Para que a liberalização comercial possa apoiar de modo mais efetivo o desenvolvimento sustentável, é necessário que os PED disponham de espaço e autonomia para utilizar políticas ativas e instrumentos de política e de regulação para promover sua capacidade de fornecimento de bens e, em especial, de serviços, ampliar os processos de assimilação de novas tecnologias e buscar competitividade. Políticas de competitividade para o desenvolvimento sustentável implicam

fortalecer e ampliar as estruturas de produção, da capacidade comercial e das instituições de políticas de um país, com o propósito de melhorar suas condições para uma integração positiva no sistema global; assegurar crescimento econômico estável no longo prazo, baseado na produção de bens e serviços que enfrente a concorrência internacional em condições justas de mercado e, ao mesmo tempo, que expanda a renda e a liberdade dos cidadãos; e usar seus recursos naturais e o meio ambiente de forma sustentável, preservando seus valores em benefício das gerações presentes e futuras. $^{(29)}$

Uma estratégia a que Corrales-Leal et al. denominam de Trade-Supported Development Strategy consistiria em administrar a integração comercial de forma a assegurar o alcance e a realização de objetivos de desenvolvimento econômico, social e ambiental. Sua viabilização compreenderia políticas comerciais em sentido estrito, de um lado, e políticas de competitividade, de outro.

Para eles, políticas comerciais nesse contexto incluiriam aquelas voltadas a obter acesso a mercado e condições comerciais justas para as exportações dos países, bem como

(28) ((As such, if they are to reverse these trends) "the terms on which this process of liberalization has been implemented - in particular the development characteristics of the multilateral system within which it operates — must be revisited".) (CORRALES-LEAL et al., 2003).

(29) ((We define "competitiveness policies for sustainable development" as the process of "strengthening and enhancing the production structures, trade capacity and policy institutions of a country, with a view to improving its ability for a positive integration into the global system; securing long term, stable economic growth, based on producing goods and services that meet freedoms of their citizens, and using their natural resources and the environment in a sustainable manner, preserving their values for the benefit of present and future generations".) (CORRALES-LEAL et al, 2003. p. 4). 
políticas com o objetivo de apoiar o lado da oferta. Isso envolveria, entre outros fatores, a liberalização de importação, apoio à capacidade de exportação e a seleção de alguns setores específicos para proteção. Políticas de competitividade abrangeriam estímulos ao desenvolvimento empresarial, de novas tecnologias e à diversificação e à consolidação de setores (CORRALES-LEAL et al., 2003, p. 17).

A conclusão fundamental a que chegam é a de que as políticas de competitividade deveriam procurar responder a duas questões essenciais, a saber: (i) como criar sistematicamente oportunidades para a diversificação da produção e da exportação tendo em vista o aumento de valor agregado e intenso conhecimento em bens e serviços?; e (ii) como reintroduzir mecanismos que transformem exportações em ampliação de ganhos equitativos e de bem-estar? (CORRALES-LEAL et al., 2003, p. 41).

No caso específico do GATS, a questão do policy space coloca ainda muitos desafios de natureza jurídica vis-à-vis o regime da OMC. O primeiro deles seria, como assinalam Howse e Teitel (2007),

(o) de identificar áreas nas quais a expansão ou flexibilidade adicional é necessária para assegurar que os membros da OMC possam cumprir suas obrigações com respeito às dimensões de segurança humana dos direitos sociais e econômicos (por exemplo, a inclusão de salvaguardas emergenciais no GATS e a criação de um porto seguro (safe haven) para subsídios, necessária para a concretização da segurança humana relacionada aos direitos humanos).

O segundo seria

(o de) identificar, com a maior precisão possível, de que forma as novas disciplinas propostas, incluindo os compromissos adicionais para a liberalização do setor de serviços, podem gerar o risco de limitação de políticas necessárias à implantação das dimensões de segurança humana dos direitos econômicos, sociais e culturais (o exemplo da privatização da água e o GATS).(so)

\section{Regulação redistributiva - Reforma do quadro Regulador}

A manutenção do policy space coloca, assim, imensos desafios. De outro lado, o próprio direito de regular (ou autonomia reguladora) assegurado no Preâmbulo do GATS precisa ser compreendido em seu sentido mais amplo, o que requer uma recalibração das prioridades, dos valores e modos de funcionamento do sistema multilateral. Essa recalibração deverá implicar a efetiva inclusão de temas relacionados a questões sociais e de desenvolvimento, que não podem ser dissociados do objetivo de liberalização do comércio internacional.

\footnotetext{
(30) ("to identify areas where enhanced or new flexibilities are required in order to ensure that WTO Members can meet their obligations with respect to human security dimensions of economic and social rights (for instance, the inclusion of emergency safeguards in the GATS and the creation of a "safe haven" for subsidies necessary for the realization of human security-related human rights);") ("to identify with as much precision as possible those instances where proposed new WTO disciplines, including additional commitments to services sector liberalization, may risk constraining policies necessary to realize the human security dimensions of economic, social and cultural rights (the example of water privatization and GATS)") (HOWSE, TEITEL, 2007. p. 12).
} 
Isso significa que o direito de regular a que se refere o Preâmbulo do GATS não deve ser entendido como algo cujo objetivo primordial seja apenas o de corrigir as falhas do mercado. A regulação tem de ser vista, de forma sistêmica, como um importante instrumento de desenvolvimento e de implantação de políticas públicas, que permita aos membros a criação de um ambiente de concorrência em benefício de sua população e, principalmente, assegure a redistribuição de renda e o acesso universal a serviços essenciais. Isso não exclui a necessidade de o Estado, via regulação, cuidar também da correção das falhas do mercado e da busca por maior eficiência econômica dos prestadores de serviços.

Significa, ademais, que se devem interpretar o Preâmbulo e o GATS como um todo à luz dos direitos humanos. Em outras palavras, não deve o GATS ser interpretado de forma a restringir a capacidade e a responsabilidade dos governos nacionais de proteger e de promover os direitos humanos. Essa leitura do GATS impõe a necessidade de se respeitarem políticas regulatórias nacionais e de que sejam assegurados o policy space e a flexibilidade para que os membros cumpram suas obrigações relativas a direitos humanos. Essas condições tornam-se evidentes, especialmente quando se analisam as características de serviços de infraestrutura ambiental, como os serviços de saneamento.

Em suma, o objetivo último da regulação - e é sob esse prisma que ela deve ser considerada no GATS - é o de endereçar questões relacionadas à redistribuição de renda, equidade, acessibilidade, qualidade e segurança dos serviços. É na redistribuição, sublinha Calixto Salomão, "que deve ser identificada a grande função do novo Estado. Trata-se, portanto, de um Estado que deve basear sua gestão (inclusive do campo econômico) em valores, e não em objetivos econômicos". A redistribuição, diz o autor,

pode ser direta - como ocorre, por exemplo, quando a regulação exige dos grandes produtores ou monopolistas que estendam seus serviços a consumidores (ou candidatos a consumidores) que a eles não têm acesso. É o que se tem, ultimamente, chamado universalização de serviços.

A universalização é, via de regra, não lucrativa, pois implica estender a rede até consumidores longínquos e sem poder aquisitivo. De outro lado, a empresa privada não estará disposta a estender a prestação de serviços simplesmente pelas externalidades sociais positivas que apresenta. Em consequência, há características que o assemelham bastante aos problemas que levaram à identificação de setores não regulamentáveis, em que a intervenção do Estado é necessária. ${ }^{(31)}$ (grifos do autor)

A manutenção do policy space e a recalibração dos valores e dos princípios embutidos no direito de regular não são suficientes. É preciso que os membros possuam um quadro

\footnotetext{
(31) SAlOMÃO FILHO, Calixto. Op. cit., p. 93/94. Enquanto serviço universal significa que o serviço tem de ser fornecido a cada pessoa ou residência individualmente, o acesso universal refere-se ao objetivo de prover a todos acesso a um determinado serviço, seja individual ou coletivamente. "A universalidade é elemento central aos dois conceitos. Em sentido amplo, está assentada em três princípios fundamentais: disponibilidade, acesso e razoabilidade de preço (affordability) ((Universality) "is central to both concepts. (In itself), it is a broad term, based on three fundamental principles: availability, access and affordability". Cf. UNCTAD - Commission on International Trade in Goods and Services, and Commodities. "Universal Access to Services", documento TD/COM.1/EM.30/2, de 18 de setembro de 2006, apresentado dois dias após a conclusão do Expert Meeting on Universal Access to Services, realizado em Genebra, de 14 a 16 de novembro de 2006. p. 3
} 
regulador doméstico afinado com esses valores e princípios que, em última instância, deverão corresponder aos interesses e aos objetivos nacionais. ${ }^{(32)} \mathrm{A}$ existência desse quadro regulador (regulatory framework) ou a necessidade de reformas internas e de adaptação para colocá-lo em vigência é condição para a liberalização do setor de serviços e para que os membros possam assumir compromissos específicos no GATS. A combinação de políticas de liberalização com regulação redistributiva é não somente um imperativo social, mas também um requisito de sustentabilidade política.

No setor de serviços de grande relevância social, tais como distribuição de água e saneamento, o processo de privatização ou de participação de agentes privados deve inserir-se em um contexto de política econômica geral desenhada por autoridades governamentais, cuja eficácia depende, em larga medida, de reformas ou ajustes regulatórios que assegurem o estabelecimento e a manutenção da concorrência, bem como o acesso universal àqueles serviços considerados essenciais. São justamente essas condições ou esses requisitos de eficácia que aproximam, na prática, as políticas de liberalização e de privatização.

A participação de agentes privados no setor de serviços essenciais de infraestrutura (água e saneamento), sobretudo estrangeiros, em alguns países da América Latina, tais como Argentina e Bolívia, revelou-se desastrosa, em face da inexistência de um quadro regulador em que estivessem assegurados os princípios do acesso universal, da equidade social, da eficiência, da modicidade de tarifas para as populações mais carentes por meio de subsídios e da independência e autonomia de agências reguladoras para regulamentar e fiscalizar a prestação de serviços.

Em outros países, como o Chile, a privatização do setor foi predominantemente benéfica para a população por força de um sistema normativo que propiciou um equilíbrio entre os interesses públicos e privados. No Brasil, há exemplos que demonstram que o setor público pode atuar eficazmente e a nova lei de saneamento (Lei n. 11.445, de 5.1.2007) aponta na direção correta de uma regulação redistributiva, sem prejuízo da participação de investimentos privados.

A experiência dos PED revela, enfim, que, para gerar resultados positivos, a liberalização do setor de serviços (i) não pode ser feita de modo demasiadamente rápido para os agentes ou operadores locais; (ii) requer segurança do quadro regulador (jurídica) e social; e (iii) pressupõe um cenário de competitividade acompanhado de políticas que assegurem e ampliem a capacidade de integração da economia local à economia global. ${ }^{(s s)}$

Outro grande desafio é o de elucidar que tipo de política deve ser adotado para os diferentes setores e subsetores de serviços e sob quais condições nacionais e internacionais

(32) A respeito, Adlung lembra com propriedade da distinção entre o direito de regular dos membros e de sua efetiva capacidade de implantar políticas relevantes. Obviamente, diz ele, "é preciso fazer uma distinção entre o direito de regular dos governos, inclusive do direito de impor obrigações de universalização, o que não é proibido pelo GATS, e sua capacidade de efetivamente conceber, implementar e executar políticas relevantes". ((OBVIOUSLY) "a distinction has to be made between governments' right to regulate, including the right to impose universal service obligations, which is not constrained under the GATS, and their ability to actually devise, implement and enforce relevant policies". (ADLUNG, 2007. p. 9).

(33) Apesar de enfocar a questão sob um viés mais liberal, Aaditya Mattoo (2005. p. 162) pondera que "administrar reformas de mercados de serviços requer, portanto, integrar abertura comercial com uma combinação cuidadosa de concorrência e regulação". 
eles podem contribuir com o crescimento econômico e o desenvolvimento sustentável. Contudo, a identificação ou negociação desses setores e subsetores não pode ser realizada sem que antes esteja em vigor um quadro regulador geral para serviços permeado pelos valores e princípios acima discutidos.

A grande maioria dos PED deverá empreender reformas para incorporar em seu quadro regulador esses valores e princípios. Essas reformas que, como discutido anteriormente, não se confundem com desregulamentação (um processo intimamente relacionado a políticas de liberalização), deverão, em muitos casos, também preceder programas de privatização. No setor de serviços, e, em especial, no de serviços de infraestrutura ambiental, os processos de privatização devem inserir-se em um contexto de política econômica geral desenhada por autoridades governamentais, cuja eficácia depende, em larga medida, dessas reformas ou dos ajustes regulatórios.

É justamente no setor de serviços ambientais que essas reformas ou esses ajustes regulatórios no âmbito interno dos membros se tornam ainda mais relevantes diante da discussão acerca dos custos e benefícios de certas negociações que estão em curso no GATS.

\section{CONSIDERAÇõES FinaIS}

No contexto do GATS, o que se nota, como visto, é um conflito potencial entre liberalização e regulação nacional. A OMC tem funcionado de modo inconsistente com seu próprio mandato. O sistema multilateral de comércio tem operado com base na crença de que os princípios neoliberais são a melhor política de desenvolvimento para os PED, enquanto os próprios países desenvolvidos buscam o maior número possível de alternativas para proteger seus setores sensíveis.

As opções de que dispõem os PED no que se refere à promoção de políticas de desenvolvimento foram reduzidas pelo disposto no regime jurídico da OMC. As normas da OMC limitaram, com maior ou menor intensidade, a capacidade dos membros de escolher os instrumentos que podem ser usados na implantação de objetivos de políticas de desenvolvimento. Quando não limitaram expressamente, deixaram em aberto essa possibilidade, qual seja, a de restrição do direito dos membros de regular ou de fazer políticas públicas (policy space) como muitos dos membros, sobretudo os desenvolvidos, fizeram no passado.

O fracasso da Conferência Ministerial de Seattle, em 1999, na qual ficou evidente a crise de legitimidade da OMC, permitiu reflexões um pouco mais equilibradas sobre os objetivos e as normas do GATS e, portanto, mais adequadas a um processo de interpretação de um Acordo-Quadro ou fórmula-compromisso. O GATS poderia e deveria ser interpretado como um instrumento de liberalização e de acesso a mercados para os prestadores de serviços estrangeiros, sem prejuízo, no entanto, da autonomia reguladora dos membros. O espaço para a implantação de políticas públicas por meio de regulação nacional deveria ser preservado, desde que não se constituísse em protecionismo ou discriminação contra provedores de serviços estrangeiros.

Isso demonstra a importância da recalibração das prioridades, dos valores e dos modos de funcionamento do sistema multilateral e, em especial, do GATS. Essa recalibração é 
necessária como forma de corrigir ou, pelo menos, diminuir o desequilíbrio operacional do sistema em favor dos países desenvolvidos. Ela poderia permitir a consolidação e a manutenção da autonomia reguladora e do policy space dos membros. Poderia possibilitar, ainda, a compreensão, em seu sentido mais amplo, do próprio direito de regular, o qual deveria incluir temas relacionados a questões sociais e de desenvolvimento. Esses temas não podem ser dissociados do objetivo de liberalização do comércio internacional de serviços.

A manutenção do policy space e a recalibração dos valores e dos princípios embutidos no direito de regular (autonomia reguladora) não são suficientes. É preciso que os membros possuam um quadro regulador doméstico afinado com esses valores e princípios que, em última instância, deverão corresponder aos interesses e aos objetivos nacionais.

A regulação tem de ser vista, de forma sistêmica, como um importante instrumento de desenvolvimento e de implantação de políticas públicas, que permita aos membros a criação de um ambiente de concorrência em benefício de sua população e, principalmente, assegure a redistribuição de renda e o acesso universal a serviços essenciais. Isso não exclui a necessidade de o Estado, via regulação, cuidar também da correção das falhas do mercado e da busca por maior eficiência econômica dos prestadores de serviços.

A existência desse quadro regulador (regulatory framework) ou a necessidade de reformas internas e de adaptação para colocá-lo em vigência é condição para a liberalização do setor de serviços e para que os membros possam assumir compromissos específicos no GATS. A combinação de políticas de liberalização com regulação redistributiva é não somente um imperativo social, mas também um requisito de sustentabilidade política.

Essas ponderações deveriam ter sempre estado presentes nas negociações do GATS. Ficaram, no entanto, durante bom tempo, eclipsadas pelos dogmas neoliberais agora postos em xeque pela crise econômica internacional. A redescoberta da importância da regulação da economia, como bem demonstra o setor de serviços, além de ser necessária ao avanço das negociações da OMC, pode também servir para reparar uma grande injustiça perpetrada por alguns fundamentalistas do mercado contra os boleros de Ravel. Ainda que repetidos e ouvidos numerosas vezes, eles continuam bonitos. Deveriam continuar a ser ouvidos e escutados. Mesmo que não se convençam disso, é improvável que discordem do fato de que certas músicas são universais e eternas, como as de Johann Sebastian Bach. Se lembrarem disso, não irão incorrer novamente nos equívocos que levaram a essa catástrofe sem precedentes na história financeira e econômica internacional.

\section{REFERÊNCIAS BIBLIOGRÁFICAS}

ADLUNG, Rudolf. The contribution of services liberalization to poverty reduction: what role for the GATS? Draft paper, 26.6.2007.

AGUILLAR, Fernando Herren. Direito econômico. Do direito nacional ao direito supranacional. São Paulo: Atlas, 2006.

BALDWIN, Robert; CAVE, Martin. Understanding regulation: theory, strategy and practice. Nova York: Oxford University, 1999. 
BAPTISTA, Luiz Olavo. O direito é história. Alocução de abertura da Conferência do Instituto de Direito do Comércio Internacional e Desenvolvimento, em São Paulo. In: BAPTISTA, Luiz Olavo; CELLI JUNIOR, Umberto, YANOVICH, Alan (orgs.). 10 anos de OMC: uma análise do sistema de solução de controvérsias e perspectivas. São Paulo: Aduaneiras, 2007.

BASSO, Maristela. Intervention of health authorities in patent examination: the Brazilian practice of the prior consent. In: CASELLA, Paulo Borba; CELLI JUNIOR, Umberto; MEIRELLES, Elizabeth de Almeida; POLIDO, Fabrício Bertini Pasquot. Direito internacional, humanismo e globalidade: Guido Fernando Silva Soares Amicorum Discipulorum Liber. São Paulo: Atlas, 2008.

BASSO, Maristela (org.). Mercosul - Mercosur. Estudos em homenagem a Fernando Henrique Cardoso. São Paulo: Atlas, 2007.

CARREAU, Dominique; JUILLARD, Patrick. Droit international économique. 4. ed. Paris: LGDJ, 1998.

CELLI JUNIOR, Umberto. Comércio de serviços na OMC. Liberalização, condições e desafios. Curitiba: Juruá, 2009.

. Investimentos internacionais e mecanismos de solução de disputas entre Estados. In: AMARAL JÚNIOR, Alberto; SANCHEZ, Michelle Ratton (coords.). Regulamentação internacional dos investimentos: algumas lições para o Brasil. São Paulo: Aduaneiras, 2007.

O caso Brasil (Embraer) x Canadá (Bombardier) na OMC. In: Comciência. Revista Eletrônica de Jornalismo Científico. Disponível em: $<$ http://www.comciencia/?section=8\&edicao=21\&id=223> Acesso em: 13.2.2007.

. Os Acordos de Serviços (GATS) e de Investimentos (TRIMS) na OMC: espaço para políticas de desenvolvimento. In: BARRAL, Welber; PIMENTEL, Luiz Otávio (orgs.). Comércio internacional e desenvolvimento. Florianópolis: Boiteux, 2006.

O Impacto dos acordos de investimentos sobre os estados-membros do Mercosul. Cadernos PROLAM/USP, São Paulo, ano 4, v. 1, 2005.

. Os países emergentes e as medidas de investimentos relacionadas ao comércio. O Acordo TRIMS da OMC. Revista da Faculdade de Direito da USP, v. 99, 2004.

CORRALES-LEAL, Werner; SUGATHAN, Mahesh; PRIMACK, David. Spaces for development policy. Revisiting special and differential treatment. Paper preparado para o ICTSD, maio 2003. Disponível em: <http://www. ictsd.org> Acesso em: 17.3.2008.

COUTINHO, Diogo R. Entre eficiência e equidade: a universalização das telecomunicações em países em desenvolvimento. Revista Direito $G V$, n. 2, 2005.

DERANI, Cristiane. Privatização e serviços públicos. As ações do Estado na produção econômica. São Paulo: Max Limonad, 2002.

FARIA, José Eduardo. O direito na economia globalizada. São Paulo: Malheiros, 1999.

HOEKMAN, Bernard. Operationalizing the concept of policy space in the WTO: beyond special and differential treatment. Journal of International Economic Law, v. 8, n. 2, 2005.

HOEKMAN, Bernard; MICHALOPOULOS, Constantine; WINTERS, L. Alan. Special and differential treatment of developing countries in the WTO: moving forward after Cancún. GREENWAY, David; WHALlEY, John (eds.). The World Economy, v. 27, n. 4. Oxford: Blackwell, 2004.

HOWSE, Robert; TEITEL, Ruti G. Beyond the divide: the covenant on economic, social and cultural rights and the world trade organization. Dialogue on Globalization, n. 30. Genebra: Friedrich Ebert Stiftung, abr. 2007. 
KRAJEWSKI, Markus. In national regulation and trade liberalization in services: the legal impact of the General Agreement on Trade in Services (GATS) on National Regulatory Autonomy. Haia, Londres, New York: Kluwer Law International, 2003.

KWA, Aileen. Rethinking the Trading System. Dialogue on Globalization, n. 32. Genebra: Friedrich Ebert Stiftung, jun. 2007.

LAFER, Celso. A OMC e a regulamentação do comércio internacional:uma visão brasileira. Por to Alegre: Livraria do Advogado, 1998.

MATTOO, Aaditya. Services in a development round: proposals for overcoming inertia. In: NEWFARMER, Richard (ed.). Trade, Doha, and development: a window into the issues. Washington: The World Bank (Trade Department), 2005.

NASSER, Rabih Ali. A OMC e os países em desenvolvimento. São Paulo: Aduaneiras, 2003.

PERRONE-MOISÉS, Cláudia. Direito a desenvolvimento e investimentos estrangeiros. São Paulo: Oliveira Mendes, 1998.

SALOMÃO FILHO, Calixto. Regulação da atividade econômica (princípios e fundamentos jurídicos). 2. ed. rev. e ampl. São Paulo: Malheiros, 2008.

$$
\text { . Regulação e concorrência (estudos e pareceres). São Paulo: Malheiros, } 2002 .
$$

SAUVÉ, Pierre. Completing the GATS Framework: Addressing Uruguay Round Leftovers. Aussenwirtschaft, Zurique, Rüegger v. III, n. 57, jan. 2002.

THORSTENSEN, Vera. OMC. As regras do comércio internacional e a nova rodada de negociações multilaterais. 2. ed. São Paulo: Aduaneiras, 2001.

\section{Jornais e revistas}

Revista Carta Capital

Jornal Gazeta Mercantil

\section{Sites}

$<$ www.ictsd.org>

$<$ www.wto.org > 